\title{
DESIGN OF PRIVATE CLOUD STORAGE USING SECURITY METHODS IDS AND IPS
}

\author{
Deval Gusrion $^{1)}$, Silky Safira ${ }^{2)}$, Retno Devita ${ }^{3)}$, Ruri Hartika Zain ${ }^{4)}$, Rini Sovia ${ }^{5)}$ \\ 1,2,3,4,5 Universitas Putra Indonesia YPTK Padang \\ Email: deval_gusrion@upiyptk.ac.id
}

\begin{abstract}
Cloud computing is a form of technological progress that has developed along with the times, this has spurred the increasing use of the internet. By usingtechnology internet that is able to implement server a virtual, which has the aim of building a cloud computing server at the District Communications and Information Office. Padang Pariaman uses the Operating System (OS) Proxmox VE (Virtual Environment) 6.4. Cloud computing is able to provide storage services that can be used simultaneously. The results of this study produce a cloud computing server that implements a security system with themethods ids (intrusion detection system) and ips (intrusion prevention system) that are able to process data(storagestorage), use software simultaneously in the network, and use infrastructure within the scope of this research.network cloud computing at the District Communications and Information Office. Padang Pariaman using aservice model private cloud.
\end{abstract}

Keywords: Cloud Computing, Proxmox, IDS, IPS

\section{INTRODUCTION}

Based on previous research conducted by Muhammad aviv natsirudin entitled ""Analysis of Cloud Technology Utilization Computing on Thin Client Networks" (Muhammad Aviv Natsirudin, 2011). explained by above only relates to the comparison and design ofsystems cloud computing, will but does not discuss the reliability of the server for the services provided [1]. Cloud computing is a computing model in which resources such aspower computing, storage media (storage), network (network) and software are run as a service through network media, it can even be accessed anywhere as long as connected to the internet. In this case to be able to build anetwork cloud computing Simplecan be done on anetwork local/intranet[2].
The application of cloud storage to information access services is virtual and can provide the best and sustainable service. Servers at the Communications Service and Access Informatics is currently able to provide services to users on a reciprocal basis back, but the server used is still temporarily storing data oncomputers client such as desktops, tablet computers, notebooks, monitors and utilization social media telegram and whatsapp. The datastorage areawill be full if at the Department of Communications and Informatics Kab. Padang Pariaman continues to carry out activities every day for an annual period. To overcome this, a solution that can be taken with method of deleting old data or by adding a new data storage area. Cloud storage is one way to solve this problem[3].

Submitted : 11-26-2021 - Accepted : 18-12-2021 - Published : 21-12-2021

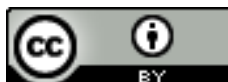

This work is licensed under a Creative Commons Attribution 4.0 International License 
The results of this study produce a cloud computing server in the form of cloud storage that applies themethods. Intrusion Data System (IDS) and Intrusion Prevention System (IPS) capable of carrying out the data storage process (storage), using software concurrentin the network, as well as the use of infrastructure and hardware within the scope of thenetwork cloud computing at the District Communications and Information Office. Padang Pariaman[4].

Computer Network is a system consisting of computers designed to be able to share resources (printers, CPUs), communicate (e-mail, instant messages), and be able to access information (web browsers). The purpose of a computer network is to achieve its goals, every part of a computer network can request and provide services. The party that requests/receives the service is called the client and the one who provides/sends the service is called the server. This design is called a client-server system, and is used in almost all computer network applications[5][6][7].

Cloud computing is amodel, client serverwhere resources such as servers, storage, network, and software can be seen as a service that can be accessed by remote users and every time. Users can enjoy various services provided by cloud computing providers, without the need to ask too much for technical assistance or support from the provider.infrastructure Cloud computing such as: servers, storage, network, and various software called "cloud[8][9][10][11].

Roxmox is a Debian-based (64 bit) virtualized Linux distribution, with KVM we can not only install Linux, but operating system we can also install the Windows, however, what makesspecial proxmox is the ease of installation and LLDIKTI Wilayah $\mathrm{X}$ web-based administration. Proxmox was developed by Proxmox Server Solutions in Austria under the Austrian Internet Foundation and released under the GPL: (General Public License), because it is ansolution open source that can be customized according to needs[12][13[][14].

Intrusion Prevention System (IPS) is a software or hardware that works for monitoring network traffic, detecting suspicious activity and taking early prevention of intrusion or events that can make the network run not as it should. IPS is an approach that is often used to build computer security systems, IPS combinestechniques firewall andmethods intrusion detection system (IDS)very well. This technology can be used to prevent attacks that will enter the local network by checking and logging all data packets and identifying packets with sensors when an attack is identified. So IPS acts like a firewall that will allow or block data packets[15].

\section{RESEARCH METHODS}

In this study, the authors observe and approach the object directly, where the object in this study is a local government company. The author approaches by observing the problem, and searching for literature on the internet. The author also conducted direct interviews with the staff in charge of the District Communications and Information Office. Padang Pariaman about the problems that exist in Diskominfo. So that the author can formulate a problem and conduct a research.

Submitted : 11-26-2021 - Accepted : 18-12-2021 - Published : 21-12-2021

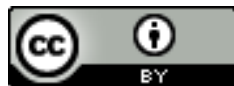

This work is licensed under a Creative Commons Attribution 4.0 International License 


\section{RESULTS AND DISCUSSION}

The results of this study are server virtualization cloud computing using Proxmox Virtual Environment 6.4 and for the configuration of the security system on thenetwork cloud using iptables on theoperating system Ubuntu. The server that is built can be managed by the administrator and accessed by the client.

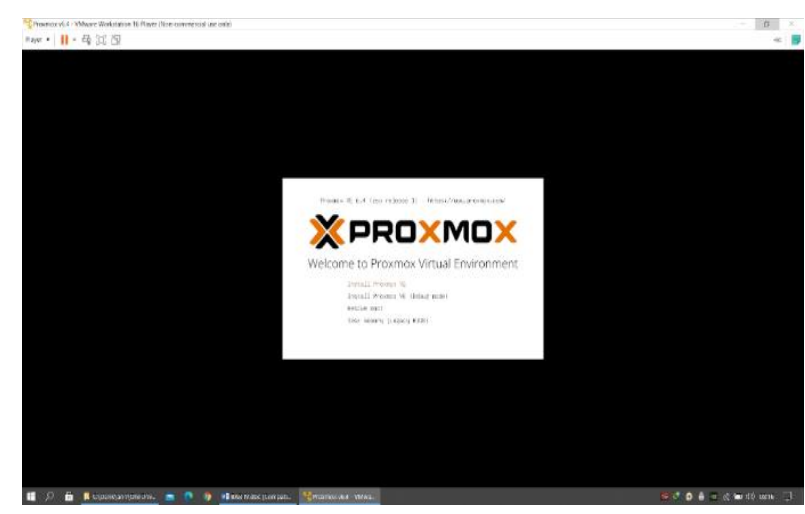

Figure 1. Promox

Proses The next process is monitoring Proxmox through the browser. Browser used in this research is Google Chrome. Protocol used i.e. HTTPS. HTTPS (Hypertext Transfer Protocol Secure) is a version of the protocol secure from HTTP overlaid with SSL (Secure Sockets Layer). With HTTPS protocol enablesclient anddata communication web server encrypted.

To monitor Proxmox on the browser, you can do this by: enter the protocol address that has been obtained after the installation process,

namely $\quad$ https://192.168.72.129:8006.

Then enter username and thepassword appropriatethat was created during installation.
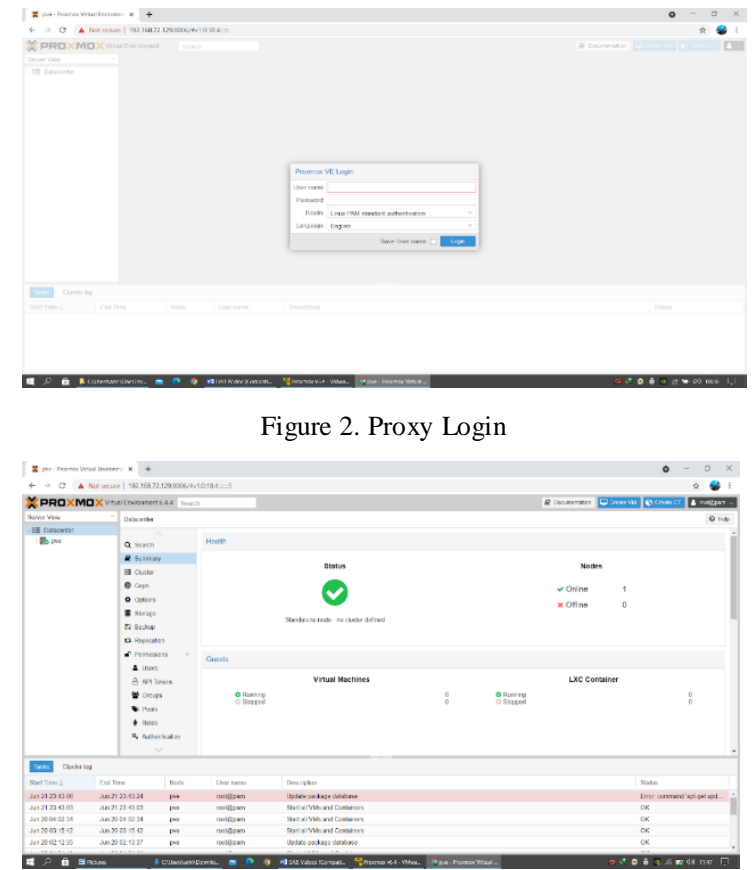

Figure 3. Initial Screen Proxmox on Browser

At this stage IPTables will be installed and configured on Linux Ubuntu 16.04 LTS virtually on VMware Workstation 16 . The installation process starts with updating and upgrading the Kernel on the operating system, installing supporting packages, and configuring IPTables rules. Install IPTables by running this command in terminal :

\# sudo apt-get install iptables-persistent -y

After viewing the conditions and configuring IPTables, then enter the rules or rules to be managed. First of all make sure that for all data packet INPUT by default is ACCEPT, this can be done with command:

LLDIKTI Wilayah $\mathrm{X}$

Submitted : 11-26-2021 - Accepted : 18-12-2021 - Published : 21-12-2021

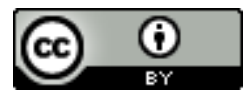

This work is licensed under a Creative Commons Attribution 4.0 International License 
\# iptables -P INPUT ACCEPT

Then to block alldata packets INPUT ,by default you can use:

\# iptables -P INPUT DROP

To open a interface particular, the parameters used are $-\mathrm{i}$ :

\#iptables -A INPUT - i eth32 -j ACCEPT

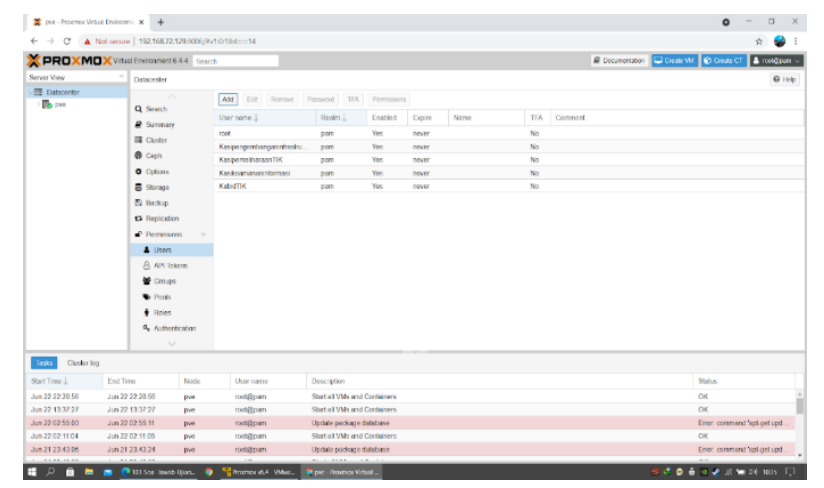

Figure 4. User Access Setting

\section{Test Result}

Results of the tests that have been carried out can be seen in the results table the following system tests :

\begin{tabular}{lllll}
\multicolumn{4}{c}{ Table 1. Testing Results Cloud Computing Server } \\
\hline No & $\begin{array}{c}\text { Access Rights } \\
\text { Client }\end{array}$ & Port & \multicolumn{2}{c}{ Login } \\
\cline { 3 - 5 } & & & Successfully & Failed \\
\hline 1. & Head of Tik & 8006 & $\checkmark$ & - \\
2. & $\begin{array}{l}\text { Head } \\
\text { Network of } \\
\text { Infrastructure } \\
\text { Development }\end{array}$ & 8006 & & - \\
3. & $\begin{array}{l}\text { Head } \\
\text { Maintenance } \\
\text { Tik }\end{array}$ & 8006 & & - \\
4. & $\begin{array}{l}\text { Head } \\
\text { Information } \\
\text { Security }\end{array}$ & & & \\
\hline
\end{tabular}

\section{CONCLUSION}

Virtualization using Proxmox VE 6.4 can be done virtually using VMware Workstation 16 as the console prompt and LLDIKTI Wilayah X configured in the browser as cloud computing. The storage service can only be accessed by running a Virtual machine on the server and configured to be a storage to be shared with fellow service users. server Thisis built in the form of virtualization with amodel private cloud so that to access the server requires LAN network access (Local Area Network). Snort IDS is a software to detect intruders and is able to analyzetraffic real-time, it can detect various types of attacks. Thefeature Snort can be a help to system and network administrators, which can warn us of potentially dangerous intruders. Theserver is IPSable to preventattacks port scanning carried out by attackers on cloud computing servers by activating thefeature firewall and configuring it with iptables

\section{REFERENCE}

[1] Ab Rahman, N. H., Cahyani, N. D. W., \& Choo, K. K. R. (2017). Cloud Incident Handling And Forensic-By-Design: Cloud Storage As A Case Study. Concurrency And Computation: Practice And Experience, 29(14), E3868

[2] Hwang, K., \& Li, D. (2010). Trusted Cloud Computing With Secure Resources And Data Coloring. Ieee Internet Computing, 14(5), 14-22.

[3] Khaldi, A., Karoui, K., Tanabène, N., \& Ghzala, H. B. (2014, April). A Secure Cloud Computing Architecture Design. In 2014 2nd Ieee International Conference On Mobile Cloud Computing, Services, And Engineering (Pp. 289-294). Ieee.

[4] Chang, V., \& Ramachandran, M. (2015). Towards Achieving Data Security With The Cloud Computing Adoption Framework. Ieee Transactions On Services Computing, 9(1), 138-151.

[5] Gaddam, R., \& Nandhini, M. (2017, March). An Analysis Of Various Snort Based Techniques To Detect And

Submitted : 11-26-2021 - Accepted : 18-12-2021 - Published : 21-12-2021

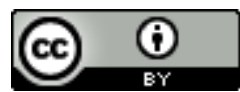

This work is licensed under a Creative Commons Attribution 4.0 International License 
Prevent Intrusions In Networks Proposal With Code Refactoring Snort Tool In Kali Linux Environment. In 2017 International Conference On Inventive Communication And Computational Technologies (Icicct) (Pp. 10-15). Ieee.

[6] Tahboub, R., \& Saleh, Y. (2014, January). Data Leakage/Loss Prevention Systems (Dlp). In 2014 World Congress On Computer Applications And Information Systems (Wccais) (Pp. 1-6). Ieee.

[7] Jaber, A. N., Anwar, S., Khidzir, N. Z. B., \& Anbar, M. (2020, December). The Importance Of Ids And Ips In Cloud Computing Environment: Intensive Review And Future Directions. In International Conference On Advances In Cyber Security (Pp. 479-491). Springer, Singapore.

[8] Okonski, A. (2018). Implementing Security Rules, Safeguards, And Ips Tools For Private Cloud Infrastructures: Groot: Infrastructure Security As A Service (Isaas).

[9] Wahyudi, A., Hadi, A., \& Sovia, R. (2020, April 29). Performance Analysis With Wireless Lan Networks Using The Quality Of Service Method. Jitce (Journal Of Information Technology And Computer Engineering), 4(01), 45-48. Https://Doi.Org/Https://Doi.Org/10.25077 /Jitce.4.01.45-48.2020.

[10] Ullah, I., Shah, M. A., Wahid, A., \& Waheed, A. (2017, April). Protection Of Enterprise Resources: A Novel Security Framework. In 2017 International Conference On
Communication (Comtech) (Pp. 98-103). Ieee.

[11] Okonski， A. (2018). Implementing Security Rules, Safeguards, And Ips Tools For Private Cloud Infrastructures: Groot: Infrastructure Security As A Service (Isaas).

[12] Bugeja, J., Jacobsson, A., \& Davidsson, P. (2016, August). On Privacy And Security Challenges In Smart Connected Homes. In 2016 European Intelligence And Security Informatics Conference (Eisic) (Pp. 172-175). Ieee.

[13] Shamshirband, S., Fathi, M., Chronopoulos, A. T., Montieri, A., Palumbo, F., \& Pescapè, A. (2020). Computational Intelligence Intrusion Detection Techniques In Mobile Cloud Computing Environments: Review, Taxonomy, And Open Research Issues. Journal Of Information Security And Applications, 55, 102582.

[14] Zhou, W., Jia, Y., Peng, A., Zhang, Y., \& Liu, P. (2018). The Effect Of Iot New Features On Security And Privacy: New Threats, Existing Solutions, And Challenges Yet To Be Solved. Ieee Internet Of Things Journal, 6(2), 16061616.

[15] Teing, Y. Y., Dehghantanha, A., Choo, K. K. R., \& Yang, L. T. (2017). Forensic Investigation Of P2p Cloud Storage Services And Backbone For Iot Networks: Bittorrent Sync As A Case Study. Computers \& Electrical Engineering, 58, 350-363.

Submitted : 11-26-2021 - Accepted : 18-12-2021 - Published : 21-12-2021

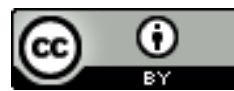

This work is licensed under a Creative Commons Attribution 4.0 International License 